
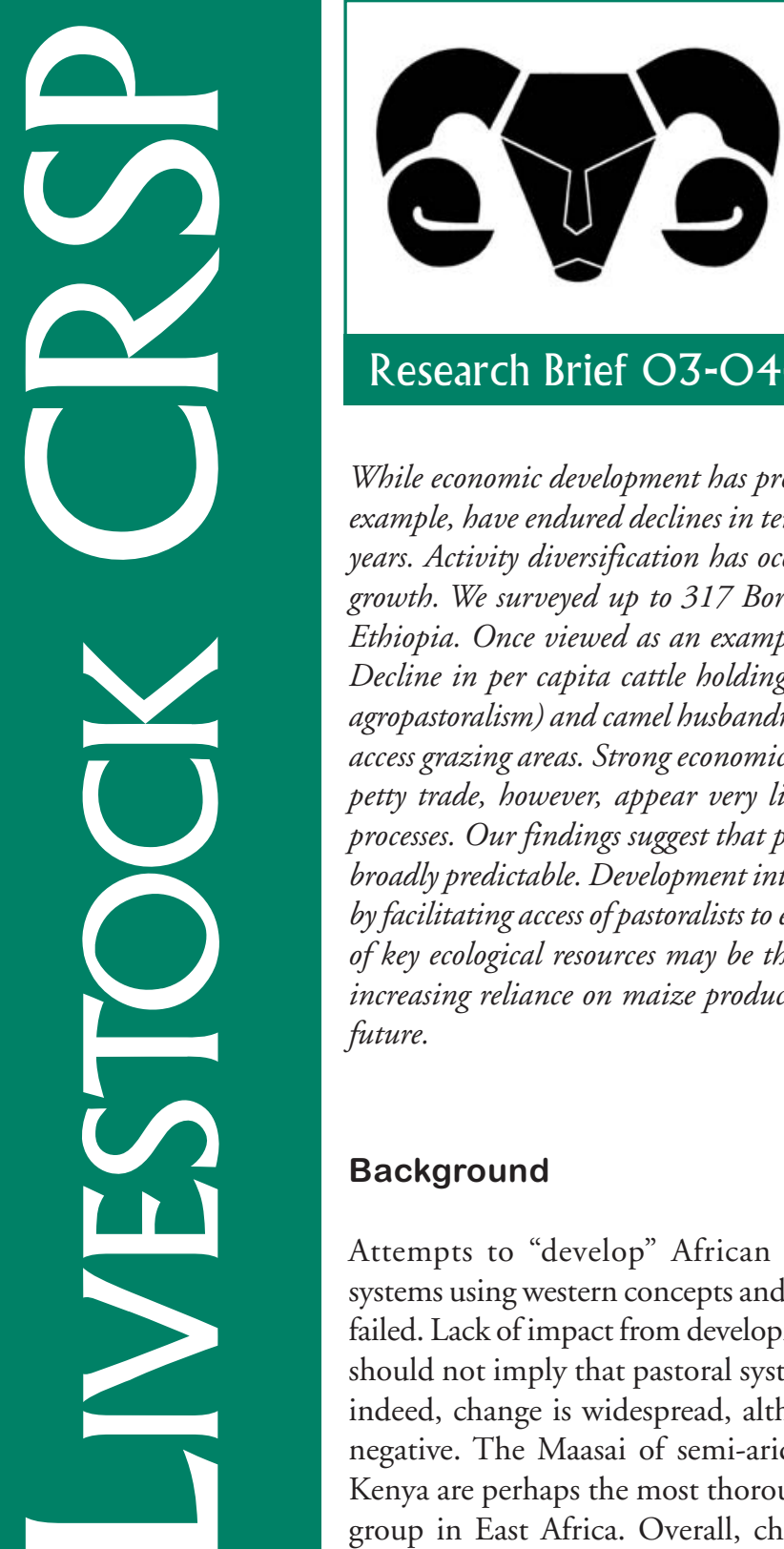

\title{
Pastoralism Under Pressure: Tracking System Change in Southern Ethiopia
}

\section{Solomon Desta and Layne Coppock, Utah State University} Pastoral Risk Management Project

While economic development has proven elusive in African pastoral systems, change is pervasive. The Kajiado Maasai, for example, have endured declines in terms of per capita livestock holdings and other aspects of human welfare over the past 50 years. Activity diversification has occurred in Maasailand as the population copes with pressure from human population growth. We surveyed up to 317 Borana households during the late 1990s to see if similar patterns occurred in southern Ethiopia. Once viewed as an example of sustainable pastoralism, the Borana system now confronts numerous challenges. Decline in per capita cattle holdings has spurred household-level diversification to include maize cultivation (emergent agropastoralism) and camel husbandry in some areas. Resource pressure has encouraged annexation of some formerly commonaccess grazing areas. Strong economic links between pastoral households and local towns, in the form of wage employment or petty trade, however, appear very limited and reflect the general isolation of the Borana pastoralists from development processes. Our findings suggest that patterns of internally induced change due to population pressure in pastoral systems are broadly predictable. Development intervention priorities should reflect system change. A focus on improving risk management by facilitating access of pastoralists to education, encouraging appropriate economic diversification, and assisting in restoration of key ecological resources may be the most appropriate development options for southern Ethiopia at this time. Shifts to increasing reliance on maize production makes these populations more at risk and more likely to require food aid in the future.

\section{Background}

Attempts to "develop" African pastoral production systems using western concepts and models have typically failed. Lack of impact from development efforts, however, should not imply that pastoral systems do not changeindeed, change is widespread, although it can often be negative. The Maasai of semi-arid Kajiado District in Kenya are perhaps the most thoroughly studied pastoral group in East Africa. Overall, change for the Kajiado Maasai over the past 50 years can be summarized as follows: (1) Decline in the ratio of cattle to people; (2) decline in the per capita milk supply for human consumption; (3) increased reliance of people on nonpastoral foods such as cereal grains; (4) increased privatization or annexation of natural resources; (5) diversified livestock holdings; and (6) increased poverty for some segments of Maasai society. One factor driving this pattern has been internal pressure from human population growth (Evangelou, 1984; Galaty, 1994; Campbell, 1999).

We have tracked the Borana pastoral system of southern Ethiopia since the 1980s to see if patterns of change resemble those observed for the Kajiado Maasai. Both systems have a traditional focus on cattle husbandry. We expected patterns to be similar, but felt that the Boran are a few decades "behind" the Kajiado Maasai. In other words, phenomena observed among the Kajiado Maasai in the 1960s or 1970s could be observable among the Ethiopian Boran today. We surveyed from 56 to 317 pastoral households across four study sites in southern Ethiopia to investigate whether livestock holdings have changed over time, how herd owners view changes in the pastoral system, and to assess whether substantial diversification of livelihoods away from traditional pastoralism was occurring (Desta, 1999). In some cases we were able to compare our data with findings from several hundred households studied in the same area during the mid- to late-1980s (Assefa, 1990; Coppock, 1994).

\section{Major Findings}

Cattle numbers per household exhibited a "boom and bust" pattern over 19 years (1980 to 1999). Cattle births and deaths are the main factors underlying the pattern. A peak of about 85 cattle per household in 1982 was reduced by $35 \%$ in the drought of $1983-5$ to 55 cattle per household. The population grew slowly back up to about 80 cattle per household by 1991 , when another dry period reduced numbers by about 47\% (Desta, 1999). The 
Table 1: Trends in the borana pastoral system as perceived by 317 herdowners ${ }^{1}$

\begin{tabular}{lccc}
\hline & \multicolumn{3}{c}{ Perceived Trend (Percent Who Agree) } \\
\cline { 2 - 4 } Feature & Decreasing & Increasing & No Change \\
\hline Access to grazing land & 91 & 7 & 2 \\
Milk for people & 97 & 1 & 2 \\
Milk for calves & 97 & 1 & 2 \\
Standard of living & 55 & 11 & 32 \\
Grain in markets & 22 & 76 & 0 \\
Pastoral grain consumption & 1 & 99 & 0 \\
Pastoral dairy sales & 29 & 71 & 0 \\
Human population & 0 & 98 & 0 \\
Need for cash income & 0 & 99 & 1 \\
Cattle production & 24 & 74 & 2 \\
Sheep production & 74 & 24 & 2 \\
Goat production & 59 & 38 & 2 \\
Camel production & 14 & 84 & 2 \\
\hline
\end{tabular}

${ }^{1}$ Some rows may not add to $100 \%$, and this is due to some respondents having "no opinion."

Note: Seventy-five percent of respondents felt that a gradual privatization of key lands due to creation of fodder reserves and cultivation, and increasing restrictions in access to the deep wells for poorer households, was reducing mobility of livestock herds (Desta, 1999).

population then grew slowly once again until 1999, when a third dry period reduced numbers by over 60\% (Shibru, 2001). We concluded that high stocking rates help set the stage for each cattle crash, and that crashes tend to be triggered by drier than average rainfall years. This implies that drought and stocking rate interact to cause livestock crashes. This pattern is very similar to the cycle recorded for Maasailand over several decades starting in the 1960s. Other details concerning the Borana cattle population are covered in PARIMA Research Brief 01-02 ("Cattle Population Dynamics in the Southern Ethiopian Rangelands").

When we compared empirical household data collected in 1997 with that for 1988, we observed several patterns. First, the number of people per household appeared to increase $36 \%$ by 1997 . Second, the number of cattle per person decreased by $19 \%$ over the same time frame. Third, the population appears to be poorer. The percentage of households ranked as "wealthy" in terms of per capita livestock holdings in 1996-7 was only about one-third of the figure estimated for 1988. Almost $50 \%$ of all of our 317 households reported a decline in wealth status (typically livestock per person) in recent times, while only $7 \%$ reported an increase in wealth status. Perceptions of how 317 herd owners see their system changing are shown in Table 1. The overall pattern strongly supports the idea that pressure is increasing over time. The availability of grazing land has reportedly declined, as has the quantity of milk for both people and calves. The vast majority of herd owners also thought that their need to sell dairy products (from an insufficient household supply) had increased, that growth in the size of the human population had occurred, and that need for cash income had increased. They felt that more grain was needed to sustain the human population. Opinions regarding production trends for livestock species were mixed, however (Table 1). Production of small ruminants was generally thought to be in decline, but camel production was strongly viewed as being on the increase-this latter point has been verified by comparing empirical household data from the mid-1980s to that from the late 1990s. Despite the periodic and deep reductions in regional cattle numbers per household in recent years (above), survey respondents tended to feel that the overall number of cattle in the region was increasing. Improved cattle health from veterinary interventions was a primary reason given for this view.

Ranked income sources for 56 households are shown in Table 2. Livestock, as the traditional source of income, was the foundation for income, although non-traditional agricultural activities such as sales of dairy products and grain were also commonly mentioned. Non-pastoral or non-agricultural income sources were very rare, however, and these were dominated by things like mining and wage labor. In general, links of pastoralists to town-based economies appear extremely limited in southern Ethiopia. Only a very few of our households had received remittances. Only 2\% of respondents had bank accounts.

The most common form of activity diversification away from traditional livestock production involved maize cultivation. We found that $67 \%$ of 311 households were routinely cultivating in 1997 , but this varied by study site. A higher percentage $(74 \%)$ of wealthy and middle-class households were cultivating compared to $61 \%$ of poorer households. The 
average plot size per household was 1.8 hectares. Maize cultivation was reportedly very rare and unsustained in the southern Ethiopian rangelands until the late 1980s (Coppock, 1994).

Only 57 of 317 households (18\%) had members with any exposure to formal education, despite that all were located within a $35-\mathrm{km}$ radius of small towns. The overall illiteracy rate (per capita) was 92\%. Those few households with links to formal education were positively associated, however, with activity diversification outside of traditional pastoral production (Desta, 1999).

\section{Practical Implications}

In general, patterns of change observed among the Ethiopian Boran appear very similar to those among well-documented groups such as the Kajiado Maasai. Human population pressure seems to be an important factor that spurs fundamental change in these pastoral systems. Differences in the extent and types of system change, however, are likely related to local and national variation in other spheres. The Ethiopian Boran appear far more isolated from development processes and external change agents than are the Kajiado Maasai, who reside near the Nairobi metropolis.

In the absence of effective external interventions - at least in the four sites we studied - the Boran appear to be coping with increased resource pressure by planting more maize, herding more camels, and annexing more forage reserves compared to that in years past. In other work it has been estimated that pure pastoralism-where milk and meat form the foundation of the food supply-can reliably support from 2-3 people per square kilometer in this system. The human population in 2003, however, is probably closer to 6 7 people per square kilometer. Livelihood changes therefore must occur for people to continue to survive in these numbers on this landscape. Grain-whether home grown or purchased-is a vital option to support a higher human carrying capacity here because of its high energy content. This may be a situation where internal pressure helps transform the production system from pastoralism to agropastoralism in areas able to support sustainable cultivation.

Maize cultivation is likely pursued because if a crop is successful, a household can reduce the chance they will have to sell animals and buy grain in the marketplace. Maize cultivation has risks, however-there may be more than an $80 \%$ chance that a maize crop will fail in the southern Ethiopian rangelands in any given year (Desta, 1999). Camels have recently become a bit more popular with the Boran because, unlike cattle that largely feed on grasses, camels feed on shrubs and trees that are not only increasing in the environment, but also tend to offer green forage for longer periods during dry seasons. The longer lactation period of camels compared to cattle may also be advantageous in terms of reducing temporal variability in household milk yields. Camels have other liabilities, however, compared to cattle. In absolute terms their numbers remain low in southern Ethiopia, they reproduce slowly, and their milk can only yield a very poor quality, waxy butter having limited utility (Coppock, 1994).

As pastoral systems change, development priorities change. For the Ethiopian Boran, a primary emphasis could now be given on how to mitigate the pressures from a growing human population. We believe more development answers lie in the risk management sphere, namely finding appropriate means for small-scale economic diversification, improving access to education, enhancing livestock marketing opportunities, and restoring key ecological resources lost from degradation or human encroachment. Other investigators (Smith et al., 2000, 2001; Little et al., 2001) have noted large differences between northern Kenya and southern Ethiopia in terms of general economic development and degree of activity diversification among pastoralists-Kenya is much more advanced in these respects. Some successes in Kenya may be transferable to southern Ethiopia.

Table 2: Ranked sources of income for 56 pastoral households on the northcentral Borana Plateau, 1996-7'

\begin{tabular}{lccccccc}
\hline & \multicolumn{7}{c}{ Income Source $^{2}$} \\
\cline { 2 - 7 } Rank & Livestock & Dairy & Wages & Grain & Gold & Salt & Other \\
\hline 1 & 43 & 0 & 2 & 2 & 1 & 1 & 5 \\
2 & 4 & 13 & 1 & 5 & 6 & 3 & 4 \\
3 & 3 & 4 & 3 & 6 & 1 & 2 & 0 \\
4 & 0 & 7 & 1 & 2 & 0 & 0 & 0 \\
\hline
\end{tabular}

${ }^{1}$ Failure of some rows to add to 56 indicates "no opinion" or missing data (Desta, 1999).

${ }^{2}$ Where "grain" implies home-grown cereals (largely maize) that was sold. Gold was typically mined from sites to the north, while salt was mined from volcanic craters to the south. "Other" income sources included cattle trading, gum arabic collection, small-scale entrepreneurial activities in towns, etc. (Desta, 1999). 


\section{References and Further Reading}

Assefa, M. 1990. “Borana Cattle Herds: Productivity, Constraints, and Possible Interventions.” Master's Thesis, Department of Rangeland Ecosystem Science, Colorado State University, Fort Collins.

Campbell, D. J. 1999. "Response to drought among farmers and herders in southern Kajiado District, Kenya: A comparison of 1972-1976 and 1994-96." Human Ecology 27(3): 377-416.

Coppock, D. L. 1994. The Borana Plateau of Southern Ethiopia: Synthesis of Pastoral Research, Development and Change, $1980-91$. Systems Study No. 5. Addis Ababa: International Livestock Centre for Africa.

Desta, S. 1999. "Diversification of Livestock Assets for Risk Management in the Borana Pastoral System of Southern Ethiopia." Ph.D. Dissertation, Department of Rangeland Resources, Utah State University, Logan.

Desta, S., and D.L. Coppock. 2002. Pastoralism under pressure: Tracking system change in southern Ethiopia. Human Ecology (submitted).

Evangelou, P. 1984. Livestock Development in Kenya's Maasailand: Pastoralists' Transition to a Market Economy. Boulder, Colorado: Westview Press.

Galaty, J. 1994. "Ha(l)ving land in common: The subdivision of Maasai group ranches in Kenya.” Nomadic Peoples 34/35: 109122.

Little, P.D., K. Smith, B. Cellarius, D.L. Coppock, and C.B. Barrett. 2001. "Avoiding disaster: Diversification and risk management among East African herders." Development and Change 32(3): 401-433.

Shibru, M. 2001. "Pastoralism and Cattle Marketing: A Case Study of the Borana of Southern Ethiopia." Master's Thesis, Department of Natural Resources, Egerton University, Njoro, Kenya.

Smith, K., C.B. Barrett, and P.W. Box. 2000. "Participatory Risk Mapping for Targeting Research and Assistance: With an Example from East African Pastoralists.” World Development 28(11): 1945-59.

Smith, K., C.B. Barrett, and P.W. Box. 2001. "Not necessarily in the same boat: heterogeneous risk assessment among East African pastoralists." The Journal of Development Studies 37(5): 1-30.

About the Authors: Dr. Solomon Desta is a postdoctoral associate in the Department of Environment \& Society at Utah State University. He represents PARIMA as Outreach Coordinator. He can be contacted via the post c/o ILRI, P.O. Box 30709, Nairobi, Kenya, or via email at S.Desta@cgiar.org.

Dr. Layne Coppock is an associate professor in the Department of Environment \& Society at Utah State University. He can be contacted via the post at the Department of Environment \& Society, Utah State University, Logan, UT 84322-5215, USA, or via email at lcoppock@cc.usu.edu.

The GL-CRSP Pastoral Risk Management Project (PARIMA) was established in 1997 and conducts research, training, and outreach in an effort to improve welfare of pastoral and agro-pastoral peoples with a focus on northern Kenya and southern Ethiopia. The project is led by Dr. D. Layne Coppock, Utah State University, Email contact: lcoppock@cc.usu.edu.

673 The Global Livestock CRSP is comprised of multidisciplinary, collaborative projects focused on human nutrition, economic growth, environment and policy related to animal agriculture and linked by a global theme of risk in a changing environment. The program is active in East Africa, Central Asia and Latin America.

This publication was made possible through support provided in part by US Universities, host country institutions and the Office of Agriculture, Economic Growth, Agriculture and Trade Bureau, United States Agency for International Development, under Grant No. PCE-G-00-98-00036-00 to University of California,

Davis. The opinions expressed herein are those of the authors and do not necessarily reflect the views of USAID.

Design by Susan L. Johnson 